\title{
VARIABILIDADE ESPACIAL DA FERTILIDADE DO SOLO EM ÁREA CULTIVADA E MANEJADA HOMOGENEAMENTE ${ }^{(1)}$
}

\author{
Zaqueu Fernando Montezano ${ }^{(2)}$, Edemar Joaquim Corazza ${ }^{(3)}$ \\ \& Takashi Muraoka ${ }^{(4)}$
}

\begin{abstract}
RESUMO
O conhecimento da variabilidade da fertilidade do solo em áreas cultivadas pode trazer importantes subsídios para a racionalização de uso dos corretivos e fertilizantes do solo. O objetivo deste estudo foi determinar a variabilidade da fertilidade do solo por meio do fracionamento de um talhão comercial em pequenas células de manejo. O experimento foi realizado na Fazenda Alto Alegre em Planaltina - GO, numa área de 373 ha de um Latossolo cultivada com milho na safra 2003/04. Traçado um polígono da área, procedeu-se à divisão em 80 células de manejo de quatro hectares cada. A amostragem do solo seguiu uma diagonal com doze pontos para formar a amostra composta representativa dentro de cada célula. As coordenadas desses pontos foram obtidas e arquivadas. Realizou-se a análise da textura do solo e da fertilidade do solo. A produtividade de cada célula foi obtida por meio da colhedora equipada com Sistema de Posicionamento Geográfico (GPS) e monitor de rendimento de grãos. Na análise da variabilidade espacial dos dados, foram considerados parâmetros estatísticos descritivos. A medida de correlação linear de Pearson a 5 e $1 \%$ dos atributos de fertilidade com a produtividade do milho e altitude foi realizada. A variabilidade foi considerada alta para o $\mathbf{P}$ disponível, Cu e Zn; média, para matéria orgânica, S, Ca, Mg, acidez potencial, soma de bases, capacidade de troca de cátions a pH 7,0, saturação por bases, B, Fe e Mn, e baixa, para $\mathrm{pH}$ e $\mathrm{K}$. Os coeficientes de correlação linear foram significativos e positivos para a matéria orgânica e boro versus produtividade do milho. Contudo, para $\mathrm{Cu}$, manganês e Zn foram significativos e negativos. Em estudos de escala de campo, normalmente não é possível isolar ou medir todos os fatores bióticos e
\end{abstract}

\footnotetext{
(1) Trabalho extraído da Dissertação de Mestrado do primeiro autor, em Solos e Nutrição de Plantas pela Escola Superior de Agricultura "Luiz de Queiroz" - ESALQ/USP. Recebido para publicação em junho de 2005 e aprovado em agosto de 2006.

${ }^{(2)}$ Doutorando em Solos e Nutrição de Plantas pela Escola Superior de Agricultura "Luiz de Queiroz" - ESALQ/USP. Laboratório de Fertilidade do Solo - CENA/USP. Av. Centenário 303, Caixa Postal 96, CEP 13416-000 Piracicaba (SP). Bolsista da CAPES. E-mail: zaqueu@esalq.usp.br

(3) Pesquisador da Embrapa Informação Tecnológica. PqEB, Av. W3 Norte, Caixa Postal 040315, CEP 70770-901 Brasília (DF). E-mail: edemar@sct.embrapa.br

${ }^{(4)}$ Professor do Centro de Energia Nuclear na Agricultura, CENA/USP. E-mail: muraoka@cena.usp.br
} 


\begin{abstract}
abióticos que influenciam a produção da cultura. Entretanto, verificou-se que o conhecimento da variabilidade da fertilidade e produtividade pode fornecer importantes subsídios para a racionalização do uso de insumos.
\end{abstract}

Termos de indexação: plantio direto, Latossolo, escala de campo, milho, Cerrado.

\title{
SUMMARY: SPATIAL SOIL FERTILITY VARIABILITY INA HOMOGENEOUSLY MANAGED CORN FIELD
}

\begin{abstract}
Insights on the variability of soil fertility in cultivated areas can contribute significantly to a rationalized use of fertilizers and soil amendments. The objective of this study was to determine the soil fertility variability through the fractionation of a commercial corn field into small management cells. The study was carried out on the farm Alto Alegre, Planaltina, GO, Brazil, on an Oxisol previously under Cerrado (savannah) in an area of 373 ha under corn in the 2003/2004 growing season. A polygon was outlined and divided into 80 management cells of 4 ha each. The soil was sampled at twelve points along the plot diagonal to constitute a representative composite sample within each cell. The coordinates of these points were obtained and recorded. The soil samples were analyzed for texture and soil fertility. The yield for each cell was obtained with a harvester equipped with a Global Positioning System (GPS) and grain yield monitor. Descriptive statistics parameters were considered in the analysis of data variability. It was carried out Pearson's simple linear correlation analysis at 5 and 1\% significance level for soil fertility versus corn grain yield and altitude data. The variability was considered high for soil available phosphorus, copper and zinc concentrations; medium for soil organic matter, sulphur, calcium, and magnesium concentrations, potential acidity, sum of bases, $C E C$, base saturation, boron, iron as well as manganese concentration, but low for soil $\mathrm{pH}$ and potassium concentration. Linear correlation coefficients (LCC) were significant and positive for soil organic matter and boron content versus corn yield. However, the LCC for copper, manganese and zinc content were significant and negative. Although it is normally not possible to isolate or measure all biotic and abiotic factors that affect the yield in field scale studies, knowledge on soil fertility variability and grain yield can contribute to a rationalization of agricultural investments.
\end{abstract}

Index terms: no-till, Oxisol, field-scale, corn, Cerrado.

\section{INTRODUÇÃO}

O Cerrado brasileiro faz parte do ecossistema das savanas que ocupa grande porção da região tropical do mundo. No Brasil, o Cerrado ocupa uma área heterogênea e não-contínua de aproximadamente 204 milhões de hectares, ou seja, $23 \%$ do território nacional. O Cerrado abrange, geralmente, áreas de relevo plano ou suave ondulado, com boas possibilidades para o emprego de práticas agrícolas mecanizadas (Goedert, 1989).

Os solos sob Cerrado, em sua maioria, apresentam propriedades que limitam o crescimento das raízes das plantas e exigem práticas de manejo adequadas. Trata-se de solos de baixa capacidade de troca de cátions (CTC), com acidez elevada e com baixo teor de nutrientes, especialmente de P. São, assim, solos com alto grau de intemperização e lixiviação, ocorrendo problemas de acidez e deficiência de nutrientes em todo perfil (Lopes, 1983; Adamoli et al., 1987; Goedert, 1989; Sousa \& Lobato, 2004).
Crescentemente, as investigações agronômicas estão explorando o uso de computadores e tecnologias de satélites aplicados como ferramentas em escala de campo, incluindo monitores georreferenciados de produtividade e dados de sensoriamento remoto e direto (Johnson et al., 2003). Agricultura de Precisão é o termo dado para uma forma de gestão das culturas, na qual as áreas de produção são manejadas com a aplicação de diferentes doses de insumos (Godwin et al., 2003). O objetivo fundamental da Agricultura de Precisão é o manejo da variação espacial nas culturas, gerando benefícios econômicos e, ou, ambientais (Taylor et al., 2003).

O reconhecimento dos limites espaciais com os equipamentos de registro da produção e controle da aplicação dos insumos agrícolas a taxas variáveis tem despertado o interesse de estudos em propriedades rurais. A pesquisa aplicada deve, por definição, fornecer informações úteis ao manejo das áreas no setor produtivo preferivelmente do que definir novos conceitos (Ikerd, 1993). Por esse motivo, é crescente 
o número de pesquisadores e produtores envolvidos em pesquisa participativa, os quais contribuem para programas de longa duração e assumem funções de liderança na identificação, localização e realização dos programas de pesquisa "on-farm" (Watkins, 1990; Rzewnicki, 1991; Gerber, 1992; Ikerd, 1993; Norman et al., 1998). Novas tecnologias usadas no manejo de áreas específicas incluem o Sistema de Posicionamento Global (GPS), o Sistema de Informações Geográficas (GIS) e o uso de sensores de avaliação direta, por exemplo, que são também mais bem avaliados em escala de campo (Heuvel, 1996).

Numa paisagem natural, o solo apresenta variabilidade espacial e temporal de seus atributos, resultante da interação de processos que comandam os fatores responsáveis por sua formação. Além disso, o solo cultivado revela fontes adicionais de heterogeneidade originadas exclusivamente pelo efeito antrópico da agricultura (Carvalho et al., 2003).

Existe certa heterogeneidade dos atributos químicos e físicos de um solo, mesmo em uma área considerada uniforme, segundo suas características visíveis de campo, tais como: topografia, cor do solo e vegetação. Para que a amostragem do solo represente, com exatidão, a sua fertilidade, é necessário o conhecimento dessa variabilidade, pois só assim as recomendações de calagem e adubação não estariam comprometidas (Santos \& Vasconcellos, 1987; Silveira et al., 2000).

Segundo Carvalho et al. (2003), a variabilidade espacial nos atributos do solo pode ser influenciada pelos seus fatores intrínsecos (fatores de formação, que são o material de origem, relevo, clima, organismos e tempo) e pelos fatores extrínsecos, normalmente relacionados com as práticas de manejo. Usualmente, uma forte dependência espacial nos atributos do solo é atribuída aos fatores intrínsecos (Cambardella et al., 1994).

Warrick \& Nielsen (1980), estudando a variabilidade de diversas propriedades do solo, verificaram que, para algumas, a variabilidade expressa pelo coeficiente de variação pode ser inferior a $10 \%$, enquanto, para outras, pode superar $1.000 \%$. Classificaram a variabilidade em três níveis: baixa $(\mathrm{CV} \leq 12 \%)$, média $(12 \%<\mathrm{CV} \leq 52 \%)$ e alta $(\mathrm{CV}>52 \%)$. Segundo Tragmar et al. (1985), propriedades do solo muito alteradas pelo manejo apresentam maior variabilidade do que aquelas relacionadas com as características morfológicas do solo (cor e horizontes), físicas (tamanho das partículas e densidade das partículas) e químicas (pH). Oliveira (1973), analisando amostras de Latossolo Roxo e Latossolo Vermelho Escuro-Orto, verificou que, para os teores de $\mathrm{Ca}, \mathrm{Mg}$, $\mathrm{K}$ e soma de bases, os coeficientes de variação foram acima de $40 \%$. Resultados semelhantes foram encontrados por Paz et al. (1996), segundo os quais o $\mathrm{pH}$, o conteúdo de $\mathrm{C}$ orgânico, a textura e a capacidade de troca cationnica apresentaram menor variabilidade que os teores de macro e micronutrientes do solo.
Souza (1992) relatou que inúmeros trabalhos têm demonstrado que os sistemas de manejo conservacionistas criam um ambiente no solo diferente do encontrado no sistema convencional, resultante dos efeitos dos resíduos superficiais e da reduzida movimentação do solo. Como resultado, tem sido encontrado um acúmulo superficial de fertilizantes nos sistemas conservacionistas (Silveira et al., 2000). A maior amplitude entre os valores dos atributos de fertilidade do solo observada no plantio direto explica os maiores coeficientes de variação (CV) nos atributos do solo nesta prática de manejo em relação às demais. Em razão do não-revolvimento do solo, como ocorre no plantio direto, espera-se maior variabilidade nos dados. Segundo Souza (1992), o sistema convencional com grade aradora apresenta menor variabilidade nos teores de matéria orgânica e nos de nutrientes da camada superficial do solo em comparação com a escarificação e o plantio direto.

A amostragem de solo para a avaliação da acidez e da fertilidade é uma prática comum nas propriedades agrícolas para aplicações de corretivos e fertilizantes de maneira uniforme. Nos últimos anos, têm crescido o interesse e a utilização de amostragens de solo na forma sistemática para a aplicação de corretivos e fertilizantes a taxas variáveis. As investigações "on farm" são tipicamente realizadas usando uma malha quadrada, espaçadas de $100 \times 100 \mathrm{~m}$, ou seja, uma amostra de solo para cada hectare (Earl et al., 2003). No Brasil, as investigações efetuadas por empresas especializadas indicam que uma amostra pode representar desde um até 20 hectares. Na amostragem, a escolha da dimensão da malha altera os custos e a criteriosidade na representação da variável a ser analisada.

O objetivo do trabalho foi avaliar a variabilidade da fertilidade do solo por meio de um fracionamento da área cultivada comercialmente em células de manejo e correlacionar os resultados obtidos com os dados de produtividade e altitude, para cada célula de manejo.

\section{MATERIAL E MÉTODOS}

O estudo foi realizado na Fazenda Alto Alegre, no município de Planaltina (GO), numa área de 373 ha. De 1987 a 1989, a área que estava sob vegetação natural de Cerrado foi desmatada para o cultivo da soja. Desde 1995, a área passou a ser cultivada em semeadura direta com o plantio de milho em rotação com soja. A área foi cultivada de maneira homogênea para fins de aplicação de insumos e manejo.

A definição dos pontos e do procedimento de amostragem do solo é descrita a seguir. O GPS etrex $v^{\text {vista }}{ }^{\circledR}$ foi utilizado para traçar uma poligonal da área. De posse do polígono, procedeu-se à divisão da área em 80 células de manejo de quatro hectares cada. As células dos limites da bordadura foram desconsideradas 
para fins de amostragem. A amostragem seguiu uma diagonal com doze pontos (subamostras) para compor a amostra composta representativa de cada uma das 80 células, as coordenadas de cada subamostra foram arquivadas para posterior utilização na obtenção dos resultados de produtividade média e altitude média. A amostragem do solo foi realizada em novembro de 2003, na profundidade de 0-20 cm, com um trado marca sondaterra com diâmetro de $2 \mathrm{~cm}$.

As amostras de solo foram secas ao ar, passadas em peneiras com malha de $2 \mathrm{~mm}$ de diâmetro e analisadas quimicamente (rotina) em relação a pH em $\mathrm{CaCl}_{2}$ 0,01 mol L-1, acidez total $(\mathrm{H}+\mathrm{Al})$, com solução de acetato de Ca, matéria orgânica (MO), pelo método espectrofotométrico; $\mathrm{P}, \mathrm{Ca}, \mathrm{Mg}$ e $\mathrm{K}$, pelo método da resina (Raij et al., 2001). Os teores de $\mathrm{Cu}$, $\mathrm{Mn}, \mathrm{Zn}$ e Fe foram determinados por uma solução extratora, o DTPA a pH 7,3 (Lindsay \& Norvell, 1978). Os teores de $\mathrm{S}\left(\mathrm{SO}_{4}{ }^{2-}\right)$ e $\mathrm{B}$ foram determinados pelo método do fosfato monobásico de Ca e por extração em água quente, respectivamente (Raij et al., 2001).

De posse dos resultados da análise do solo, foram calculados os seguintes atributos de fertilidade: soma de bases (SB), CTC a pH 7,0 (T) e saturação por bases (V) (Sousa \& Lobato, 2004). A análise granulométrica do solo (conteúdo de areia, silte e argila) foi realizada por meio do método do densímetro (Embrapa, 1997).

Os dados de produtividade do talhão foram obtidos no momento da colheita, por meio de colhedora equipada com sistema de posicionamento geográfico (GPS), sensor de fluxo de grãos por placa de impacto, sensor de umidade de grãos, sensor de velocidade de deslocamento da colhedora e sensor de controle de altura da plataforma. Essas informações foram gerenciadas pelo monitor de rendimento de grãos AgLEADER PFAdvantage ${ }^{\circledR}$ que arquivou as leituras de produtividade, altitude e umidade de grãos a cada dois segundos, durante a colheita da cultura em toda a área.

O Sistema de Informação Geográfica (SIG) foi utilizado para visualizar os dados brutos de produtividade de grãos e altitude. A partir desses dados, pôde-se fazer a interpolação, pelo método do inverso do quadrado da distância, para geração dos mapas (Figura 1). Os dados médios de produtividade e altitude, para cada uma das 80 células de manejo, foram identificados pelo SIG. Os pontos georreferenciados das subamostras do solo e os mapas de dados brutos de produtividade e altitude foram sobrepostos. Em cada ponto de subamostra, foram selecionados os dados de produtividade e altitude, contidos em um círculo com $10 \mathrm{~m}$ de raio, e calculouse a média. As médias de produtividade e altitude de cada subamostra serviram para obter as respectivas médias de cada uma das 80 células de manejo (Shiratsuchi \& Machado, 2003).

$\mathrm{Na}$ análise estatística dos resultados, foi considerado o cálculo dos parâmetros estatísticos referentes às medidas de tendência central e variabilidade, para cada conjunto de valores. Foram calculados os coeficientes de assimetria e curtose, para analisar o tipo e o formato da curva de distribuição dos resultados de cada atributo do solo. A medida de correlação linear do coeficiente de Pearson serviu para analisar a correlação entre os atributos do solo e as médias de produtividade do milho e altitude da área, em cada célula de manejo, a 5 e $1 \%$, pelo teste t. $\mathrm{O}$ software Statistic for Windows Statsoft (1996) foi o pacote estatístico utilizado nas análises.

\section{RESULTADOS E DISCUSSÃO}

\section{Variabilidade da textura do solo}

Os parâmetros estatísticos descritivos calculados a partir dos teores de areia, silte e argila, encontramse no quadro 1. Verifica-se a não-normalidade da distribuição desses atributos do solo. Primeiramente, o valor correspondente à média e à mediana não coincide, presumindo tratar-se de uma distribuição assimétrica. Outro fato é que os coeficientes de assimetria foram diferentes de zero, com valor negativo para argila, indicando assimetria negativa para a distribuição dos teores. Esses resultados concordam com os encontrados por Cambardella et al. (1994).

Os coeficientes de assimetria e de curtose dos atributos são apresentados para efeito de comparação com a distribuição normal, para o qual esses coeficientes são, respectivamente, zero e três.

Comparativamente, a menor variabilidade foi encontrada para o atributo argila. Segundo Warrick \& Nielsen (1980), porém, os valores dos coeficientes de variação para os três atributos estão contidos dentro do intervalo correspondente à interpretação de média variabilidade $(12 \%<\mathrm{CV} \leq 52 \%)$. Salviano et al. (1998) encontraram valor próximo do coeficiente de variação para o silte, porém o maior e o menor coeficiente corresponderam à argila e areia, respectivamente. O tipo de solo pode estar influenciando estes resultados invertidos, uma vez que, para aquele trabalho, foram avaliados os atributos de um Podzólico Vermelho-Amarelo. Por serem atributos não influenciados pelas práticas de manejo da cultura e por apresentarem uma estabilidade maior no tempo, pode-se dizer que a variabilidade que apresentam é intrínseca, ou seja, é devida à variação natural no solo.

\section{Variabilidade dos atributos de fertilidade do solo}

A maioria dos atributos químicos do solo não apresentou ajuste a uma distribuição normal (Quadro 1). como também constataram outros autores (Carvalho et al., 2003; Salviano et al., 1998; Cambardella et al., 1994). A camada de solo, utilizada para amostragem, é mais afetada pelo processo de mecanização, manejo das culturas e erosão. Alguns 
Quadro 1. Medidas estatísticas descritivas de atributos físicos e químicos do solo estudado

\begin{tabular}{|c|c|c|c|c|c|c|c|}
\hline \multirow{3}{*}{ Atributo } & \multicolumn{7}{|c|}{ Medida estatística descritiva } \\
\hline & \multirow[b]{2}{*}{ Média } & \multirow[b]{2}{*}{ Mediana } & \multirow{2}{*}{ Desvio-padrão } & \multirow{2}{*}{ Variância } & \multicolumn{3}{|c|}{ Coeficiente } \\
\hline & & & & & Variação & Assimetria & Curtose \\
\hline Areia $\left(\mathrm{g} \mathrm{kg}^{-1}\right)$ & 134,63 & 120,00 & 67,22 & 4518,84 & 49,93 & 1,70 & 2,35 \\
\hline Silte $\left(\mathrm{g} \mathrm{kg}^{-1}\right)$ & 208,88 & 190,00 & 50,47 & 2546,82 & 24,16 & 1,86 & 5,53 \\
\hline Argila (g kg-1) & 656,50 & 685,00 & 97,55 & 9516,71 & 14,86 & $-1,42$ & 1,42 \\
\hline $\mathrm{pH}\left(\mathrm{CaCl}_{2}\right)$ & 4,83 & 4,80 & 0,17 & 0,03 & 3,54 & 0,70 & 0,96 \\
\hline $\mathrm{MO}\left(\mathrm{g} \mathrm{kg}^{-1}\right)$ & 46,79 & 48,50 & 7,78 & 60,47 & 16,62 & $-0,89$ & 0,10 \\
\hline $\mathrm{P}\left(\mathrm{mg} \mathrm{kg} \cdot{ }^{-1}\right)$ & 22,24 & 19,45 & 11,57 & 133,82 & 52,02 & 1,54 & 2,21 \\
\hline $\mathrm{SO}_{4}^{2-}\left(\mathrm{mg} \mathrm{kg}^{-1}\right)$ & 8,21 & 7,30 & 3,01 & 9,04 & 36,63 & 0,88 & 0,14 \\
\hline $\mathrm{K}\left(\mathrm{mmol}_{\mathrm{c}} \mathrm{kg}^{-1}\right)$ & 2,84 & 2,83 & 0,32 & 0,10 & 11,25 & 0,61 & 0,29 \\
\hline $\mathrm{Ca}\left(\mathrm{m} \mathrm{mol}_{\mathrm{c}} \mathrm{kg}^{-1}\right)$ & 26,08 & 26,12 & 4,93 & 24,35 & 18,92 & 0,10 & $-0,26$ \\
\hline $\mathrm{Mg}\left(\mathrm{m} \mathrm{mol}_{\mathrm{c}} \mathrm{kg}^{-1}\right)$ & 8,74 & 8,46 & 1,94 & 3,77 & 22,20 & 0,68 & 0,03 \\
\hline $\mathrm{H}+\mathrm{Al}\left(\mathrm{mmol}_{\mathrm{c}} \mathrm{kg}^{-1}\right)$ & 54,06 & 54,00 & 11,07 & 122,46 & 20,47 & $-0,27$ & $-0,51$ \\
\hline $\mathrm{SB}\left(\mathrm{mmol}_{\mathrm{c}} \mathrm{kg}^{-1}\right)$ & 37,66 & 37,25 & 6,38 & 40,76 & 16,94 & 0,18 & $-0,17$ \\
\hline $\mathrm{CTC}\left(\mathrm{mmol}_{\mathrm{c}} \mathrm{kg}^{-1}\right)$ & 91,72 & 94,78 & 13,45 & 180,79 & 14,66 & $-0,25$ & 0,03 \\
\hline $\mathrm{V}(\%)$ & 41,31 & 41,04 & 6,05 & 36,64 & 14,64 & 0,23 & $-0,33$ \\
\hline $\mathrm{B}\left(\mathrm{mg} \mathrm{kg}{ }^{-1}\right)$ & 0,43 & 0,40 & 0,08 & 0,01 & 19,70 & 0,18 & $-0,52$ \\
\hline $\mathrm{Cu}\left(\mathrm{mg} \mathrm{kg}^{-1}\right)$ & 0,44 & 0,34 & 0,27 & 0,07 & 60,53 & 1,53 & 1,65 \\
\hline $\mathrm{Fe}\left(\mathrm{mg} \mathrm{kg}^{-1}\right)$ & 18,42 & 17,61 & 3,52 & 12,39 & 19,11 & 0,94 & 1,22 \\
\hline $\operatorname{Mn}\left(\mathrm{mg} \mathrm{kg}^{-1}\right)$ & 1,73 & 1,41 & 0,84 & 0,70 & 48,58 & 1,92 & 2,92 \\
\hline $\mathrm{Zn}\left(\mathrm{mg} \mathrm{kg}^{-1}\right)$ & 2,16 & 1,63 & 1,38 & 1,91 & 63,86 & 1,25 & 1,43 \\
\hline Produtividade $\left(\right.$ tha $\left.^{-1}\right)$ & 7,84 & 7,81 & 0,43 & 0,19 & 5,48 & $-0,24$ & $-0,32$ \\
\hline Altitude (m) & 1068,4 & 1071,0 & 19,85 & 393,86 & 1,86 & $-0,17$ & $-1,02$ \\
\hline
\end{tabular}

atributos, como pH, K, Ca, $\mathrm{H}+\mathrm{Al}$ e B, apresentaram uma tendência à distribuição normal. Os valores das medidas estatísticas de tendência central foram praticamente iguais para estes atributos. Também os coeficientes de assimetria para esses atributos estiveram mais próximos de zero.

O menor coeficiente de variação encontrado foi de $3,54 \%$, para o $\mathrm{pH}$, e o maior, de $63,86 \%$, para o $\mathrm{Zn}$. Adotando o critério proposto por Warrick \& Nielsen (1980) para esta medida estatística de dispersão, os seus valores revelaram-se como (Quadro 1): (a) altos, para $\mathrm{P}, \mathrm{Cu}$ e $\mathrm{Zn}$, corroborando com os resultados de Carvalho et al. (2003), Silveira et al. (2000) e Salviano et al. (1998), para o P, e com os de Silveira \& Cunha (2002), para $\mathrm{Cu}$ e Zn; (b) médios para matéria orgânica (MO), $\mathrm{S}\left(\mathrm{SO}_{4}^{-2}\right), \mathrm{Ca}, \mathrm{Mg}$, acidez potencial $(\mathrm{H}+\mathrm{Al})$, soma de bases (SB), CTC a pH 7,0, saturação por bases (V), B, Fe e Mn, concordando estes resultados com os de Carvalho et al. (2003), Silveira et al. (2000) e Salviano et al. (1998); (c) baixos, para acidez ativa ( $\mathrm{pH}$ ) e $\mathrm{K}$, concordando apenas para $\mathrm{pH}$ com os resultados obtidos por Carvalho et al. (2003), Silveira et al. (2000) e Salviano et al. (1998).

Há certa similaridade entre os atributos $\mathrm{H}+\mathrm{Al}$ e CTC, como constataram Salviano et al. (1998). Isto pode ser explicado pelo fato de $\mathrm{H}+\mathrm{Al}$ exercer influência direta no cálculo da CTC, o qual poderá ser observado pela correlação entre esses dois atributos. A análise envolvendo $\mathrm{CTC}$ e $\mathrm{H}+\mathrm{Al}$ deve ser vista com reserva, como alertaram Carvalho et al. (2003). É necessário lembrar que a CTC é o somatório de K, Ca, Mg $\mathrm{e} \mathrm{H}+\mathrm{Al}$ e que solos com o mesmo valor de CTC apresentarão $\mathrm{H}+\mathrm{Al}$ com valores distintos, dependendo do $\mathrm{pH}$.

A alta variabilidade para os teores de $\mathrm{P}$ pode ser atribuída à aplicação de fertilizantes em linha, ao efeito residual da adubação e à exposição de camadas mais pobres desse nutriente, pelo processo de erosão superficial, como listaram Salviano et al. (1998).

Como a camada de solo considerada na amostragem é a mais afetada pelo processo de mecanização, pelas atividades de manejo da cultura e pelos processos de erosão superficial e lixiviação de nutrientes, era esperado que a maioria dos atributos determinados no solo não apresentassem ajuste a uma distribuição normal.

\section{Variabilidade da produtividade do milho}

Observa-se que, na parte central da área, as produtividades de milho foram maiores, acima de 
$8,3 \mathrm{t} \mathrm{ha}^{-1}$ (Figura 1a). As menores produtividades ocorreram próximo aos limites da área, abaixo de $7,3 \mathrm{t} \mathrm{ha}^{-1}$. As diferenças de produtividade na área manejada homogeneamente demonstram que, para um mesmo custo de produção, a renda obtida para cada célula analisada mostrou-se diferente. $\mathrm{O}$ relevo da área foi classificado como suave ondulado, como pode ser observado no mapa de superfície da altitude da área (Figura 1b).

\section{Correlações com a produtividade da cultura do milho}

Uma vez que trabalhos demonstraram que a produtividade vegetal acompanha a distribuição de nutrientes no solo (Vieira et al., 1987; Miller et al., 1988; Bhatti et al., 1991), foi realizada a correlação dos resultados dos atributos do solo com os dados de produtividade e entre esses atributos.

A análise de correlação revelou que, dentre os maiores coeficientes encontrados, destacam-se aqueles que explicam a relação linear entre as medidas de acidez do solo $(\mathrm{pH}$ e $\mathrm{H}+\mathrm{Al})$ e o teor de $\mathrm{MO}$ com a soma de bases (SB), a CTC e a saturação por bases (V) (Quadro 2). Destacam-se também para as correlações entre os micronutrientes e as medidas de acidez do solo $(\mathrm{pH}$ e $\mathrm{H}+\mathrm{Al})$ e os teores de $\mathrm{MO}$. Dentre os nutrientes analisados, os micronutrientes foram os elementos que, em sua maioria, apresentaram coeficientes significativos com tais atributos (Quadro 2). Considerando os micronutrientes, particular atenção é dada para o Cu e o Mn, os quais apresentaram correlações negativas com a acidez potencial $(\mathrm{H}+\mathrm{Al})$, a CTC e teor de $\mathrm{MO}$.

Pode-se inferir pelos resultados que a menor disponibilidade de $\mathrm{Cu}$ e $\mathrm{Mn}$ no Cerrado está mais fortemente ligada às causas do sistema plantio direto, o qual proporciona um aumento do teor de MO na camada superficial do solo. A presença da MO no solo está associada com a disponibilidade e retenção de alguns micronutrientes no solo, como o $\mathrm{B}$, $\mathrm{Cu}$ e $\mathrm{Zn}$. Deficiências de $\mathrm{Fe}, \mathrm{Cu}, \mathrm{Mn}$ e, ou, $\mathrm{Zn}$ têm sido verificadas em solo com alto teor de $\mathrm{MO}$, em decorrência da sua ação quelante sobre esses íons. À medida que esta se decompõe, ocorre a liberação de micronutrientes (Oliveira et al., 1999).

Os coeficientes de correlação entre os atributos do solo e os dados de altitude da área foram maiores em comparação aos coeficientes calculados para esses atributos e os dados de produtividade (Quadro 2). Podese inferir que estes atributos estão relacionados, em

\section{(a)}
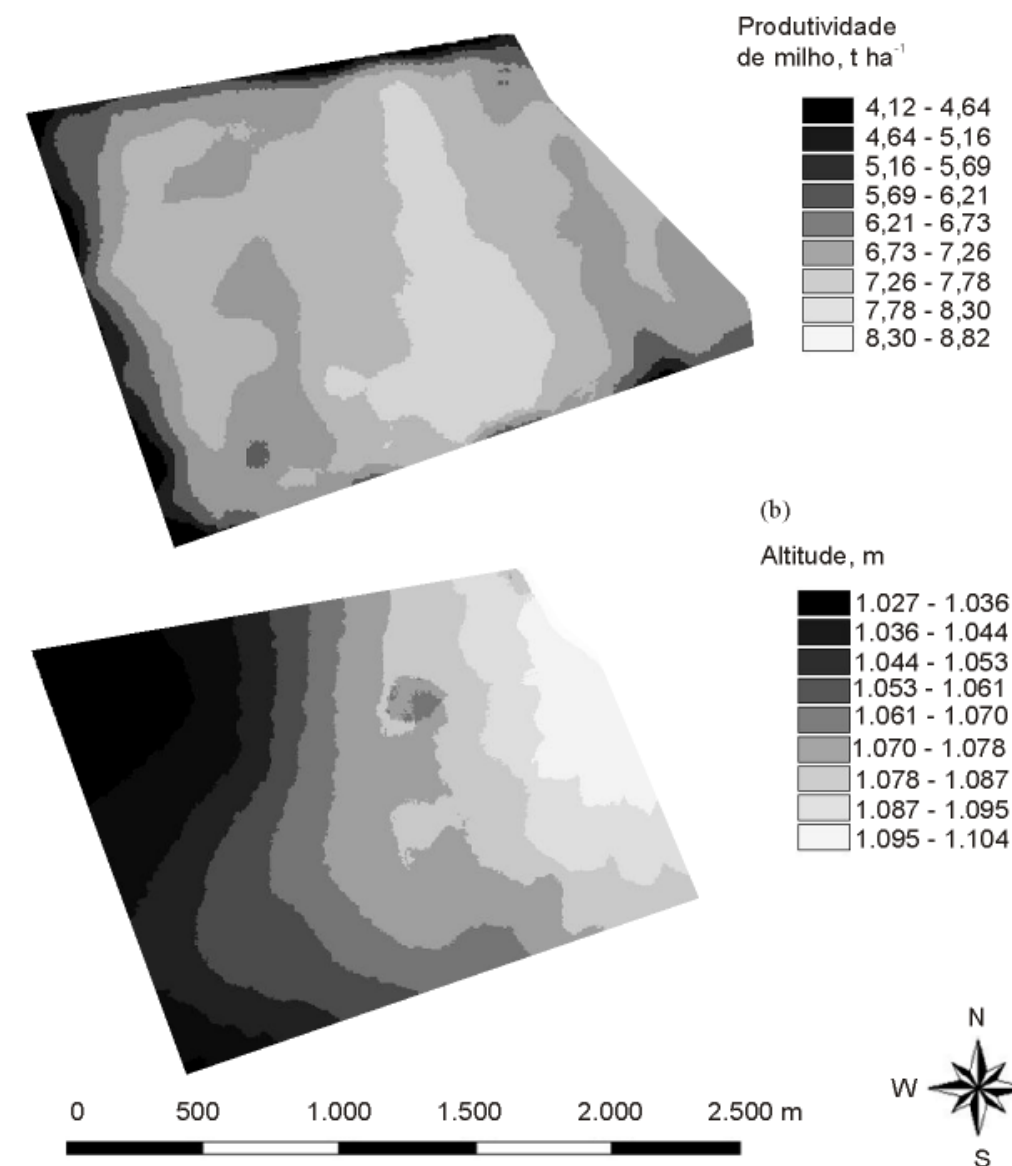

Altitude, $m$

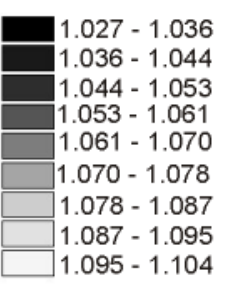

Figura 1. Mapas de produtividade de grãos de milho (a) e altitude em relação ao nível do mar (b). 
Quadro 2. Correlação linear de Pearson entre os atributos de fertilidade do solo, as produtividades médias de milho e as altitudes médias da área ${ }^{(1)}$

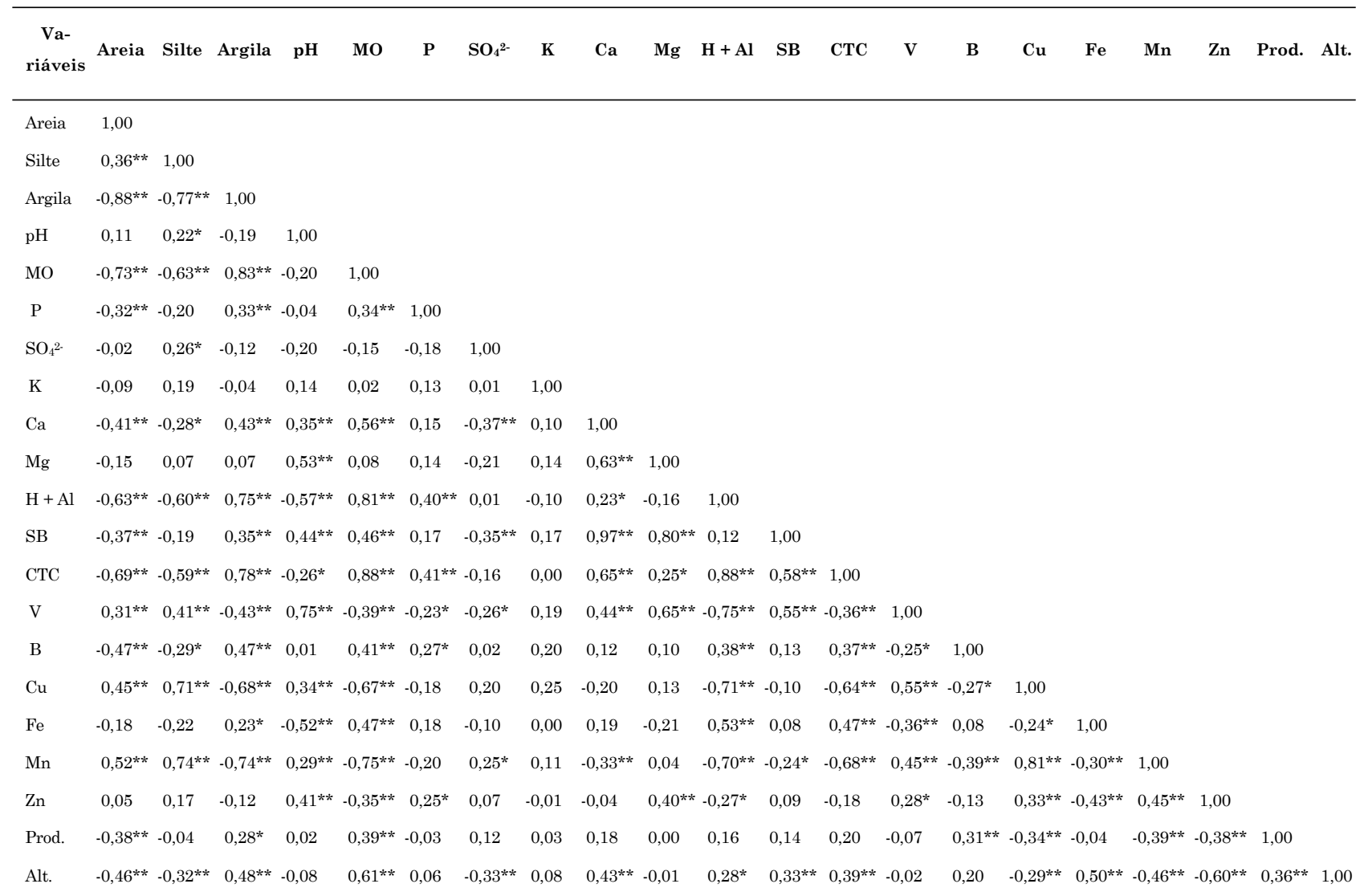

* e **: Significativos a 5 e $1 \%$, respectivamente, pelo teste t.

maior grau, com os fatores de formação do solo, neste caso o relevo, do que com a produtividade, exceto para $\mathrm{V}, \mathrm{B}$ e $\mathrm{Cu}$.

Em estudos de escala de campo, não é possível isolar ou medir todos os fatores bióticos e abióticos que influenciam a produção da cultura. Neste estudo, os coeficientes de correlação linear de Pearson para a maioria dos atributos de fertilidade do solo versus produtividade do milho não foram significativos a $5 \%$, com exceção da $\mathrm{MO}$ e dos micronutrientes $\mathrm{B}, \mathrm{Cu}, \mathrm{Mn}$ e Zn (Quadro 2).

A análise de correlação entre os atributos de fertilidade do solo e os dados de produtividade de grãos na cultura do milho revelaram que os coeficientes significativos de correlação foram baixos, ou seja, menores que 0,50, de modo geral. Destaque para as correlações negativas entre os teores de $\mathrm{Cu}, \mathrm{Mn}$ e $\mathrm{Zn}$ com os dados de produtividade. Para os coeficientes positivos de correlação entre os atributos de fertilidade e os dados de produtividade, vale destacar aquele que relaciona a $\mathrm{MO}$ com a produtividade.

$\mathrm{O}$ coeficiente significativo entre a $\mathrm{MO}$ e a produtividade demonstra a influência na disponibilidade de nutrientes às plantas e a importância desta como condicionadora da qualidade física de solos cultivados sob sistema plantio direto.

Os coeficientes de correlação negativos significativos para $\mathrm{Cu}, \mathrm{Mn}$ e $\mathrm{Zn}$ versus produtividade estão diretamente ligados ao fornecimento anual destes nutrientes, juntamente com as adubações dos macronutrientes, e ao fato de o solo apresentar uma acidez elevada caracterizada pela média do $\mathrm{pH}$ em $\mathrm{CaCl}_{2}$ de 4,8, demonstrando, assim, um possível efeito negativo na produtividade pelos teores médios e altos de $\mathrm{Cu}, \mathrm{Mn}$ e $\mathrm{Zn}$ no solo.

Pode-se notar um comportamento semelhante dos dados de produtividade e altitude com relação aos atributos de fertilidade. A altitude como medida indireta do relevo da área, por inferência, é a que mais influencia os resultados desses atributos, comparativamente aos dados de produtividade.

\section{CONCLUSÕES}

1. Os atributos de fertilidade do solo apresentaram de baixa a alta variabilidade para a área de estudo. 
2. As recomendações de calagem para a correção da acidez do solo e de adubações para os próximos cultivos a serem realizados na área devem considerar a variabilidade espacial da fertilidade do solo.

3. Em escala de campo, as correlações lineares dos atributos da fertilidade do solo com a produtividade da cultura foram baixas, uma vez que não foi possível isolar todos os fatores envolvidos.

4. O manejo da matéria orgânica do solo foi fundamental para melhorar a produtividade dos cultivos.

\section{AGRADECIMENTOS}

Aos proprietários da Fazenda Alto Alegre, pelo apoio na realização do trabalho. Ao pesquisador da Embrapa Cerrados, Luciano Shozo Shiratsuchi, pela colaboração na realização do mapa de produtividade e de altitude.

\section{LITERATURA CITADA}

ADÁMOLI, J.; MACÊDO, J.; AZEVEDO, L.G. \& MADEIRA NETTO, J. Caracterização da região dos Cerrados. In: GOEDERT, W.J., ed. Solos dos Cerrados: tecnologias e estratégias de manejo. São Paulo, Nobel, 1987. p.33-74.

BHATTI, A.U.; MULLA, D.J. \& FRAZIER, B.E. Estimation of soil properties and wheat yields on complex eroded hills using geostatistics and thematic mapper images. Remote Sens. Environ., 37:181-191, 1991.

CAMBARDELLA, C.A.; MOORMAN, T.B.; NOVAK, J.M.; PARKIN, T.B.; KARLEN, D.L.; TURCO, R.F. \& KONOPKA, A.E. Field-scale variability of soil properties in Central Iowa Soils. Soil Sc. Soc. Am. J., 58:1501-1511, 1994.

CARVALHO, M.P.; TAKEDA E.Y. \& FREDDI, O.S. Variabilidade espacial de atributos de um solo sob videira em Vitória Brasil (SP). R. Bras. Ci. Solo, 27:695-703, 2003.

EARL, R.; TAYLOR, J.C.; WOOD, G.A.; BRADLEY, R.I.; WAINE, T.; WELSH, J.P.; KNIGHT, S.M. \& GODWIN, R.J. Soil factors and their influence on within-field crop variability, part I: Field observation of soil variation. Biosys. Eng., 84:425-440, 2003.

EMPRESA BRASILEIRA DE PESQUISA AGROPECUÁRIA EMBRAPA. Manual de métodos de análise do solo. Rio de Janeiro, 1997. 212p.

GERBER, J.M. Farmer participation in research: A model for adaptive research and education. Am. J. Altern. Agric., 7:118-121, 1992.

GODWIN, R.J.; RICHARDS, T.E.; WOOD, G.A.; WELSH, J.P. \& KNIGHT, S.K. An economic analysis of the potential for precision farming in UK cereal production. Biosys. Eng., 84:375-391, 2003.
GOEDERT, W.J. Região dos Cerrados: Potencial agrícola e política para seu desenvolvimento. Pesq. Agropec. Bras., 24:1-17, 1989 .

HEUVEL, R.M. van der. The promise of precision agriculture. J. Soil Water Conser., 51:38-40, 1996.

IKERD, J.E. The question of good science. Am. J. Altern. Agric., 8:91-92, 1993

JOHNSON, C.K.; ESKRIDGE, K.M.; WIENHOLD, B.J.; DORAN, J.W.; PETERSON, G.A. \& BUCHLEITER, G.W. Using electrical conductivity classification and within-field variability to design field-scale research. Agron. J., 95:602613,2003

LINDSAY, W.L. \& NORVELL, W.A. Development of a DTPA soil test for zinc, iron, manganese and copper. Soil Sci. Soc. Am. J., 42:421-428, 1978.

LOPES, A.S. Solos sob Cerrado: Características, propriedades e manejo. Piracicaba, Potafos, 1983. 162p.

MILLER, M.P.; SINGER, M.J. \& NIELSEN, D.R. Spatial variability of wheat yield and soil properties on complex hills. Soil Sci. Soc. Am. J., 52:1133-1141, 1988.

NORMAN, D.W.; BLOOMQUIST, L.E.; FREYENBERGER, S.G.; REGEHR, D.L., SCHURLE, B.W. \& JANKE, R.R. Farmers attitudes concerning on farm research: Kansas survey results. J. Nat. Res. Life Sci. Educ., 27:35-41, 1998.

OLIVEIRA, J.B. Variação de características morfológicas, físicas e mineralógicas em duas áreas de Oxissolo. Piracicaba, Escola Superior de Agricultura "Luiz de Queiroz", 1973. 199p. (Tese de Doutorado)

OLIVEIRA, J.J.; CHAVES, L.H.G.; QUEIROZ, J.E. \& LUNA, J.G. Variabilidade espacial de propriedades químicas em um solo salino-sódico. R. Bras. Ci. Solo, 23:783-789, 1999.

PAZ, A.; TABOADA, M.T. \& GÓMEZ, M.J. Spatial variability in topsoil micronutrient contents in a one-hectare cropland plot. Comm. Soil Sci. Plant Anal., 27:479-503, 1996.

RAIJ, B. van; ANDRADE, J.C.; CANTARELA, H. \& QUAGGIO, J.A. Análise química para avaliação da fertilidade de solos tropicais. Campinas, Instituto Agronômico, 2001. 285p.

RZEWNICKI, P. Farmer's perceptions of experiment station research, demonstrations, and on farm research in agronomy. J. Agric. Educ., 20:31-36, 1991.

SALVIANO, A.A.C.; VIEIRA, S.R. \& SPAROVEK, G. Variabilidade espacial de atributos de solo e de Crotalaria juncea L. em área severamente erodida. R. Bras. Ci. Solo, 22:115-122, 1998

SANTOS, H.L. \& VASCONCELLOS, C.A. Determinação do número de amostras de solo para análise química em diferentes condições de manejo. R. Bras. Ci. Solo, 11:97$100,1987$.

SHIRATSUCHI, L.S. \& MACHADO, A.L.T. Variação do espaçamento entre faixas de colheita na geração de mapas de produtividade. Planaltina-DF, Embrapa Cerrados, 2003. 25p. (Boletim de Pesquisa e Desenvolvimento, 90) 
SILVEIRA, P.M. \& CUNHA A.A. Variabilidade de micronutrientes, matéria orgânica e argila de um Latossolo submetido a sistemas de preparo. Pesq. Agropec. Bras., 37:1325-1332, 2002.

SILVEIRA, P.M.; ZIMMERMANN, F.J.P.; SILVA, S.C. \& CUNHA, A.A. Amostragem e variabilidade espacial de características químicas de um Latossolo submetido a diferentes sistemas de preparo. Pesq. Agropec. Bras., 35:2057-2064, 2000.

SOUSA, D.M.G. \& LOBATO, E., eds. Cerrado: correção do solo e adubação. 2.ed. Brasília, Embrapa, 2004. 416p.

SOUZA, L.S. Variabilidade espacial do solo em sistemas de manejo. Porto Alegre, Universidade Federal do Rio Grande do Sul, 1992. 162p. (Tese de Doutorado)

STATSOFT. Statistica for windows. v.6.0. Tulsa, 1996.
TAYLOR, J.C.; WOOD, G.A.; EARL, R. \& GODWIN, R.J. Soil factors and their influence on within-field crop variability, Part II: Spatial analysis and determination of management zones. Bios. Eng., 84:441-453, 2003.

TRANGMAR, B.B.; YOST, R.S. \& UEHARA, G. Application of geostatistics to spatial studies of soil properties. Adv. Soil Sci., 38:45-94,1985.

VIEIRA, S.R.; DE MARIA, I.C.; CASTRO, O.M.; DECHEN, S.C.F. \& LOMBARDI NETO, F. Utilização da análise de Fourier no estudo do efeito residual da adubação em uva na crotalária. R. Bras. Ci. Solo, 11:7-10, 1987.

WARRICK, A.W. \& NIELSEN, D.R. Spatial variability of soil physical properties in the field. In: HILLEL, D., ed. Applications of soil physics. New York, Academic Press, 1980. cap.13, p.319-344.

WATKINS, G. Participatory research: a farmer's perspective. Am. J. Alter. Agric., 5:1069-1083, 1990. 